\title{
Legado de Amílcar Cabral: entre a dimensão humana e o exemplo de revolucionário*
}

Apesar de não ser especialista em estudos e obras de Amílcar Cabral, mas permitam-me que enquanto dirigente do PAIGC, partido criado por ele, onde pude ao longo dos anos de intervenção política, militância e de participação em vários seminários, colóquios e simpósios realizados em diversas ocasiões, obter e capitalizar alguns conhecimentos sobre a longa trajetória do homem político, do revolucionário, do estratégia militar, do diplomata, do pedagogo, do poeta e do fundador da nossa nacionalidade; - que passo a partilhar convosco.

O tema escolhido obrigou-me a uma passagem obrigatória não só pelos ensinamentos do pensamento político, filosófico, cultural e social refletidos nas ações deste grande filho de África, mas também pelo exemplo de vida do homem, do combatente infatigável e intransigente dos Direitos Humanos para todos os povos explorados, oprimidos e discriminados. Nas várias intervenções e subsídios deixados ao mundo por Amílcar Cabral, é notório a desconcertante simplicidade, que coexistia quase sempre com a complexidade dos temas em que refletiu, e das tarefas que assumiu por decisão própria. Como ele mesmo dizia, e passo a citar: "sou um simples africano que dedicou toda a sua capacidade e competência à causa do homem, à sua liberdade e à sua afirmação plena..." fim de citação. E permitam que perante esta afirmação proferida na primeira pessoa, não encontre melhor adjetivo do que HUMANISTA para esta nobre postura.

E, sobre o homem, não se pode ainda esquecer, por mais sucinta que seja a anotação, a referência ao técnico, ao engenheiro agrônomo que, com grande exigência e rigor científico, fez a sua formação universitária, em Lisboa, com excelentes notas, estudou a erosão dos solos no Alentejo no Sul de Portugal e a morte súbita do cafeeiro em Angola, fez um dos melhores recenseamentos agrícolas da história da Guiné-Bissau onde também sentiu a necessidade de estudar a nossa história e compreender a estratificação étnico-social os usos e costumes dos povos que habitam o atual território do Estado da Guiné-Bissau.

Num trabalho praticamente antropológico, fez um levantamento cabal, das línguas e tradições próprias e, concebeu padronizações feitas até hoje, no nosso país ao reconhecer nas etnias do litoral a ausência de classes, a que designou de sociedades horizontais (na maior parte dos casos de religiões animistas), enquanto que as do interior, com uma estratificação social avançada e muito mais desenvolvida politicamente, a que designou de sociedades verticais (na maior parte dos casos de religiões islâmica).

Trago também, algumas reflexões e espero que contribuam para alargar o âmbito do reconhecimento e uma melhor compreensão do percurso político de Amílcar Cabral e de alguns princípios que nortearam a ação ideológica do partido PAIGC.

Ao fazer referência ao homem, ao técnico e ao revolucionário, decorre a importância da ligação entre teoria e prática. A obra teórica de Amílcar Cabral parte de um conhecimento muito profundo da realidade da Guiné- 
-Bissau e de Cabo Verde e visa à aplicação política mais eficaz desse conhecimento quando escolhe como títulos para os livros- "A Prática Revolucionária -” ou “A arma da teoria - unidade e luta" é esclarecedora e eficaz, pois traduz a procura constante em fazer da teoria, do estudo, da reflexão, a grande arma para a prática revolucionária. E hoje existem fatos que provam que não foram dogmas, e muito menos histórias únicas (contadas só de um lado), quando temos conhecimento que a Universidade de Estocolmo está a trabalhar na reedição destes fascículos e que a Universidade da Califórnia em Santa Bárbara pretende lançar programas de mestrado sobre as suas teses políticas e sociais.

A obra teórica de Amílcar Cabral coloca-se para a luta armada de libertação nacional, numa relação dialética perfeita. O seu rigor deriva de uma prática política, a muitos títulos exemplares e permite-lhe constituir-se na principal mola impulsionadora da própria luta.

Por essa razão, a obra teórica de Amílcar Cabral, suscita por um lado uma leitura imediata à prática revolucionária para a luta de Libertação Nacional e por outro, deixa em aberto a leitura do seu sentido mais profundo

- A construção da Justiça Social, do progresso, do bem estar e da felicidade do nosso povo.

A grandeza de Amílcar Cabral resulta não só da dimensão da obra que ele foi capaz de realizar, mas também do valor do seu comportamento exemplar como simples pessoa humana, como cidadão do mundo.

Amílcar Cabral, foi um autêntico revolucionário, foi um homem à frente da sua época, sensível às realidades do seu tempo e capaz de assimilá-las e fazer galvanizar as suas ideias, foi um verdadeiro patriota, amando profundamente não só o seu povo, mas sim todos os povos do mundo, sobretudo os povos sujeitos à exploração, ao obscurantismo, à fome, à miséria e à opressão. Daí o seu humanismo e o seu espírito profundamente internacionalista.

Os ensinamentos de Amílcar Cabral mostram sempre como alguém com elevada formação acadêmica e moral se preocupa com o destino dos outros e deu provas disso desde a sua juventude, quando ainda estudante em Cabo Verde e Portugal.

Nos anos 40 e 50 do século passado, ele toma posição contra a política e Estatuto Político Civil e Criminal dos Indígenas, vulgo "Estatuto do Indigenato", que foi um instrumento que permitiu aos seus promotores organizar e potenciar os desígnios coloniais que passaram pela ocupação das terras, condição primeira para a plena e efetiva colonização. Posteriormente também esteve na linha da frente no combate ao "Estatuto do assimilado" que era a despersonalização levada a cabo pelo colonialismo português e afirma a sua condição de homem africano, lançando em Portugal, com outros jovens estudantes das ex-colônias as bases culturais do primeiro movimento político unitário africano.

Para levar à Cabo o seu projeto revolucionário, Amílcar Cabral, tira maior partido possível da sua formação acadêmica, técnica e da sua cultura profundamente impregnada de humanismo progressista.

Intelectual revolucionário, mas também homem de massas, Amílcar Cabral pôde a partir de certas constatações baseadas na realidade objetiva, orientar devidamente os seus esforços para a criação de uma organização política, capaz de permitir que as ideias de libertação nacional penetrassem nas massas populares .

Durante os anos que precedem o da criação do PAIGC - Partido Africano para a Independência da Guiné e Cabo Verde, Amílcar Cabral revela-se como o precursor do pensamento e ação unitários, como um organizador de talento, um teórico de grande valor e sobretudo um revolucionário de ação e de pensamento.

A criação do PAIGC nos finais do anos 50, inscreve-se na linha natural e lógica da evolução do pensamento de Amílcar Cabral.

Depois da criação do PAIGC, a história veio confirmar, que para um povo se libertar de um jugo colonial, ou de uma dominação estrangeira, é indispensável que haja um instrumento político capaz de defender os interesses e aspirações das massas dominadas e exploradas.

Contudo, se a existência de tal instrumento político é uma condição necessária, ela nem sempre é suficiente. A experiência vivida por alguns povos do continente africano, e não só, mostra que em certos casos, frentes de luta, movimentos ou partidos não conseguiram atingir os objetivos justos que se propunham, no sentido da libertação dos povos, cuja luta dirigiam contra uma dominação estrangeira.

Entre estas ideias-chave, se junta outra: a relevância do fator cultural. E Amílcar Cabral dizia "cada povo 
deve poder dar a sua contribuição própria ao patrimônio mundial, graças a uma produção cultural original e dinâmica, verdadeiramente popular e livre de se exprimir criativamente" fim de citação.

A nossa história (GUINÉ-BISSAU), mostra que o PAIGC, foi instrumento que possibilitava o nosso povo a criar a unidade temida pelo exercício da exploração e dominação colonial. A defesa intransigente que Amílcar Cabral faz do princípio da "unidade" e "luta" não é pois um ato fortuito, uma ideia a mais, mas sim um fruto amadurecido e conscientemente padronizado pelo seu pensamento e pela sua ação.

A aplicação intransigente desse princípio está na base de todos os grandes sucessos conseguidos pelo PAIGC, durante a luta armada de libertação nacional e permitiu forjar na sequencia do tempo, pouco a pouco uma consciência nacional e assim a Nação Africana.

Uma das maiores glórias de Amílcar Cabral, para além da criação do PAIGC e de ser fundador da nossa nacionalidade, foi a de ter levado o Partido a criar uma vida nova nas regiões libertadas, forjando assim um "homem novo", conscientizado, e com uma outra concepção do mundo. Com a luta o povo Guineense, aprendeu a ser cada vez mais internacionalista, pôde conhecer outros povos, aprender com eles e ensinar-lhes algo em contra partida, num verdadeiro princípio de partilha e de reciprocidade do conhecimento.

A perenidade de qualquer formação política e da sua ideologia assenta nos seus princípios e nos seus valores. O PAIGC é um partido dotado de princípios sólidos e valores altruístas concebidos pelo seu fundador e baseados na realidade concreta e histórica da nossa terra. No seu celebre discurso pronunciado na $1^{\text {a }}$ Conferência da Tri Continental em Havana-Cuba, Amílcar Cabral defendeu; cito: “A deficiência ideológica, para não dizer, a falta de ideologia por parte dos movimentos de libertação nacional - que tem a sua justificação de base na ignorância da realidade histórica que esses movimentos pretendem transformar - constitui uma das maiores, senão a maior fraqueza de sua luta", fim de citação.

A luta do povo, pelo povo, para o povo, "era a máxima de Cabral", e é um dos princípios mais importantes do PAIGC sobre o qual Amílcar Cabral insistia; que a nossa luta era a luta do nosso povo e o nosso povo é que tinha que a fazer, e o seu resultado era para o nosso povo.
Não era possível conceber a libertação, a paz e o progresso de nossa terra, chamando pessoas de fora para lutar. A luta de libertação era para o nosso povo, porque seu objetivo e o seu fim eram para satisfazer as suas aspirações, os seus sonhos e os seus desejos de ter uma vida digna, decente, como desejam todos os povos do mundo; que desejam ter o respeito, a paz para construir os progressos na sua terra, para construir felicidade para os seus filhos.

$\mathrm{Na}$ abordagem deste auspicioso princípio, Amílcar Cabral sempre dizia, cito: "Nós queremos que tudo quanto conquistamos nesta luta pertença ao nosso povo e temos que fazer o máximo para criar uma tal organização, que mesmo que cada um de nós queira desviar às conquistas da luta para seus interesses, o nosso povo não deixe”. Fim de citação.

Um outro princípio sagrado do PAIGC é o da independência do pensamento e de ação. A aplicação desses princípios levavam os dirigentes, responsáveis e militantes do Partido, a serem livres na maneira de pensar e de resolver os problemas. Nessa ordem de ideia, Amílcar Cabral insistia muito dizendo: cito "Temos que ser cada dia mais capazes de pensar muito nos nossos problemas para podermos agir bem, e agir muito, para podermos pensar cada vez melhor". Fim de Citação.

Foram apenas alguns princípios do PAIGC, que consideramos importantes, como elementos de ensinamentos de Amílcar Cabral, que devidamente aplicados, não de forma dogmática, podem contribuir consideravelmente para o reforço e consolidação do processo democrático, multipartidário da Guiné-Bissau e fortificar, cada vez mais a democracia nos países que cooperam com a Guiné-Bissau.

No contexto atual, não se coloca a questão de saber se os princípios político-ideológico, adotados pelo PAIGC são corretos ou não. A correção de um ou outro desses princípios, não podem ser determinadas em função das deficiências que possam caracterizar a sua prática. O mais que se possa fazer é imputar o erro de não cumprimento ou cumprimento inadequado dos mesmos aos autores que, conscientemente, os adotaram como guia para a sua ação.

A título ilustrativo, no caso do PAIGC, seria irrealista conferir o mesmo conteúdo, de ontem e de hoje, ao princípio de unidade e luta. 
Durante a Luta de Libertação Nacional, o objetivo da "unidade" e da "luta" era claro, palpável, aglutinador e profundamente sentido por todos aqueles que aderiram à luta contra a presença e exploração colonial. Esse sentimento ou consciência comum, base da unidade obtinha, no dia-a-dia da luta expressões e repercussões concretas na vida dos combatentes do PAIGC e das populações.

É fácil constatar hoje, que essas motivações cederam lugar outros fatores que convém não só identificar teoricamente, como fazer deles pontos concretos de referência no cotidiano do nosso povo.

O Programa maior do Partido coloca, com clareza, os magnos objetivos da etapa pós-independência, em que a "unidade" e a "luta" continuam decisivas na dupla perspectiva de consolidação da Nação Guineense, e da libertação das forças produtivas rumo à verdadeira independência.

No entanto, contrariamente ao que acontecia durante a Luta de Libertação Nacional, a realidade prática continua aquém das expectativas das camadas que ontem sustentaram o combate conta a dominação estrangeira, suscitando, por vezes, dúvidas ou um menor ou maior cepticismo quanto à validade dos fundamentos políticos-ideológicos de um processo que demora em materializar os sonhos de bem-estar, progresso e justiça social prometidos desde o limiar da luta político-armado de libertação nacional.

A "Unidade", como instrumento, visando a consecução dos objetivos programáticos do Partido, resulta de um processo em que esse princípio deve evidenciar-se, na prática, como um meio indispensável para garantir o êxito final. A capacidade de Amílcar Cabral, com o seu rigor e exigência do ponto de vista técnico-científico, seria determinante no equacionar e na resolução de dificuldades deste projeto tão inovador e ambicioso que era a formação de uma Nação guineense Justa e Solidária.

Esse processo não é automático, atuando nele elementos contraditórios e às vezes, antagônicos. Assim, e para citar apenas alguns desses elementos, registra-se a presença na nossa realidade social, para além da heterogeneidade étnica e dos exclusivismos ainda nela inerentes, uma integração cultural, econômica e política nacional lenta, uma estratificação social cada vez mais diversificada, com o seu leque de consciências, objetivos e interesses, um desequilíbrio entre a cidade e o campo é ainda muito notório, entre outros.
Face às importantes transformações que se verificaram na economia guineense, no início da década de 90, o PAIGC teve que protagonizar mudanças profundas no sistema político da Guiné-Bissau, desviando assim de certa maneira dos ensinamentos básicos de Amilcar Cabral.

O PAIGC e a sociedade guineense chegaram à conclusão que um sistema multipartidário, que permitisse as pessoas exprimirem-se livremente em organizações políticas diferentes, com regras devidamente estabelecidas, constituía a forma mais avançada da prática da democracia participativa.

Da abertura ao sistema político multipartidário à data presente, juntaram-se ao PAIGC mais três dezenas de formações políticas, para um universo de eleitores de aproximadamente seis centos mil.

Constata-se a ausência total de ideologia cotidiana da maioria das formações políticas, que, normalmente, só intervêm no cenário político durante as eleições - legislativas e presidências. Parafraseando Amílcar Cabral, essa ausência de ideologia - que tem a sua justificação de base na ignorância da realidade histórica em que intervêm essas formações políticas - constitui a sua maior fraqueza.

As consequências de certa falta de abertura e capacidade de diálogo, de ambição desmedida, bem como de tal prática de agir para depois pensar são as que a sociedade guineense se vem confrontando nos últimos tempos. Com efeito, a aplicação inadequada das regras de conveniência democrática estabelecidas, provoca distorções no sistema político, nomeadamente a constituição de Governo na base dos resultados das eleições legislativas e até presidenciais, contrariamente ao preceituado na Constituição da República. No início da abertura ao multipartidarismo na Guiné-Bissau, falou-se muito do problema desse sistema em África, da questão da unidade nacional e dos perigos inerentes à existência de diferentes grupos étnicos, isto é, a existência de solidariedade étnica.

Efetivamente, esses laços de solidariedade étnica podem ser mal aproveitados, como dizia Amílcar Cabral, por indivíduos que já não estão e nem pertencem cultural e religiosamente a essas etnias, mas que podem aproveitar-se dessa solidariedade para atingirem os seus fins próprios, para conseguirem finalidades próprias, que não têm nada a ver com as etnias. 
Infelizmente, assiste-se atualmente a esse fenômeno, em que muitos partidos e personalidades políticas aproveitam dessa solidariedade étnica para promover políticas contrárias à unidade nacional, desviando assim dos ensinamentos de Cabral, no intuito apenas de satisfazer as suas ambições políticas, pessoais, particularmente durante as eleições. Essas lutas não se revestem de um caráter linear, mas têm sido grande entrave para o amadurecimento político do povo guineense.

Estas foram algumas reflexões que quis trazer aqui para, com os participantes deste $1^{\circ}$ Seminário, trocar opiniões e proceder a uma análise crítica e pragmática da obra científica e da ação revolucionária de Amílcar Cabral, numa perspectiva dinâmica, enquadrada no tempo e no contexto em que vivemos.
Como é evidente não se pode esgotar, apenas com esta pequena dissertação, uma reflexão cabal sobre Amílcar Cabral. A grandeza dos seus ensinamentos multifacetada e multidimensional, pode proporcionar sessões especiais de reflexão sobre: Amílcar escritor e poeta. Amílcar precursor da política do gênero tão propalado hoje, como podem constatar ao longo desta minha modesta contribuição, parafraseando os ensinamentos de Amílcar Cabral no atual contexto político da Guiné-Bissau, ficamos sem saber o que mais lembrar e admirar de Cabral: - Se a dignidade do homem; - Se a profundidade do pensador; - Se a coragem do militante; - Se a firmeza e coerência do político da sua época. É com esta dimensão humana que Amílcar Cabral, marcou no século passado, profundamente a nossa história, deixando seu legado para as gerações e gerações vindouras. 
Para publicar na revista

Universitas Relações Internacionais,

entre no endereço eletrônico www.publicacoesacademicas.uniceub.br. Observe as normas de publicação, facilitando e agilizando o trabalho de edição. 